\section{Bond Strength of Experimental Root Canal Sealers Based on MTA and Butyl Ethylene Glycol Disalicylate}

\author{
Marina Carvalho Prado ${ }^{1}$, Nancy Kudsi de Carvalho ${ }^{1}$, Rafael Pino Vitti ${ }^{2}$, Fabrício \\ Aulo Ogliari ${ }^{3}$, Luciana Moura Sassone ${ }^{1}$, Emmanuel João Nogueira Leal Silva ${ }^{1,4}$
}

\author{
1 PROCLIN Department, School \\ of Dentistry, UERJ - Universidade \\ Estadual do Rio de Janeiro, \\ Rio de Janeiro, RJ, Brazil \\ ${ }^{2}$ Department of Prosthodontics, \\ Dentistry School, UNITAU \\ - Universidade de Taubaté, \\ Taubaté, SP, Brazil \\ ${ }^{3}$ Dental Materials Division, School \\ of Dentistry, UFPel - Universidade \\ Federal de Pelotas, Pelotas, RS, Brazil \\ ${ }^{4}$ Department of Endodontics, \\ UNIGRANR10 - Universidade Grande \\ Rio, Rio de Janeiro, RJ, Brazil \\ Correspondence: Marina Carvalho \\ Prado, Estrada do Campinho, 298 \\ A. Campo Grande, 23070-220 \\ Rio de Janeiro, RJ, Brazil. Tel/ \\ Fax: +55-21-2413-1442. e-mail: \\ marinaprado@dentistas.com.br
}

This study investigated the bond strength of two experimental root canal sealers based on MTA and butyl ethylene glycol disalicylate: MTAe and MTAe-HA. The reference materials used for comparison were AH Plus and MTA Fillapex. Twenty human upper incisors were selected and one $1 \mathrm{~mm}$ slice was obtained from the cervical third of each root. On the coronal surface of each slice, four $0.9 \mathrm{~mm}$ wide holes were drilled through the dentine. Standardized irrigation was performed and holes were filled with one of the four tested sealers: AH Plus, MTA Fillapex, MTAe, and MTAe-HA. The filled slices were stored in a PBS solution ( $\mathrm{pH}$ 7.2) for 7 days at $37^{\circ} \mathrm{C}$. A push-out assessment was performed with a $0.7 \mathrm{~mm}$ plunger tip. Load was applied at a crosshead speed of $0.5 \mathrm{~mm} / \mathrm{min}$ until sealer displacement. The results were expressed in MPa. The Kruskal-Wallis test was applied to assess the effect of each sealer on the push-out bond strength. Mann-Whitney with Bonferroni correction was used to isolate the differences. The alpha-type error was set at 0.05 . Significant differences among medians values obtained by materials were observed $(p<0.001)$. AH Plus displayed the highest value of bond strength $(p<0.001)$. In contrast, MTA Fillapex presented the lowest bond strength among all tested sealers $(p<0.001)$. Experimental sealers showed intermediary bond strength values, with no statistical differences between them $(p>0.05)$. In conclusion, experimental root canal sealers presented suitable bond strength outcomes when compared to MTA Fillapex.
Key Words: dental materials, MTA, push-out, root canal obturation, root canal sealer.

\section{Introduction}

Mineral trioxide aggregate (MTA) is a calcium-silicate cement broadly used in endodontics that has vast evidence supporting this material (1). Despite presenting considerable advantages, such as the ability to set in the presence of moisture $(1,2)$, low cytotoxicity (3), bioactivity $(1,4,5)$, restricted microleakage $(3)$, biocompatibility $(3)$, and some antimicrobial activity (1), MTA is not indicated to be used as a root canal sealer with conventional root canal filling techniques, especially because of its setting time (1), working time (1), and difficult handling $(1,2)$ and removal in cases of root canal retreatment $(1,2)$. Thus, several associations have been proposed with the intention to extrapolate the MTA's remarkable balance between biological and physicochemical properties, creating a close-to-ideal sealer (5-8).

MTA Fillapex (Angelus, Londrina, Paraná, Brazil) is a paste-paste calcium-silicate-based sealer designed in an attempt to produce a root canal sealer with the biological and sealing properties of MTA cement (5). Basically, it is composed of MTA, salicylate resin, natural resin, bismuth, and silica. Although the manufacturer claimed that this sealer has adequate working time, easy handling, excellent radiopacity, and low solubility, it has produced inconsistent results related to biological and physicochemical properties $(5,6)$. MTA Fillapex presents excessive flow ability $(6)$ and has displayed high and long-lasting cytotoxic effects (5). The presence of MTA has not shown to present biocompatibility advantages or to improve bone-tissue repair (8). Moreover, several studies revealed low values for MTA Fillapex's resistance to displacement $(7,10)$. This sealer is used as a reference material mainly because it was the first MTAcontaining sealer and it is internationally available and frequently used by clinicians $(5,6,9)$.

Experimental MTA and butyl ethylene glycol disalicylate-based sealers have been proposed (6). These sealers basically contain a base paste (butyl ethylene glycol disalicylate and bismuth oxide) and a catalyst paste (MTA, titanium dioxide, and $\mathrm{N}$-ethyl-o,p-toluenesulfonamide [Resimpol 8], with or without the addition of a calcium phosphate such as hydroxyapatite [HA]). The butyl ethylene glycol disalicylate present in the base paste is a salicylate resin, which is a chemical compound usually found in the content of oils and anti-inflammatory creams (11). The use of derivatives of salicylates resins presenting differences in the molecular structure permit to reach resins/polymers 
with different physical characteristics - as handling properties and rheological characteristics (6). Several root canal sealers also exhibit salicylate resin on its composition, such as MTA Fillapex and Sealapex (Sybronendo, Glendora, USA). The experimental sealers containing butyl ethylene glycol disalicylate showed some improved physicochemical properties when compared to MTA Fillapex, such as the working and setting time and the capacity to release calcium ions (6). Nevertheless, their bond strengths to root dentine have not been evaluated yet. This study proposed a recent method of push-out assessment that is capable of increasing the internal validity related to dentine source and standardization of root canal anatomy (9). For that, artificial holes were created in the same dentine source, instead of preparing several teeth presenting different anatomy and analyzing some root regions as it is accomplished in conventional push-out designs $(13,14)$.

In this context, this study investigated the bond strength of two experimental MTA and butyl ethylene glycol disalicylate-based sealers - MTAe and MTAe-HA with the aim to evaluate their performance in a relevant physical aspect for clinical application, increasing the overall knowledge about these materials that have potential $\vec{\sigma}$ to become a clinical alternative of root canal sealers. MTA Fillapex and AH Plus (Dentsply, DeTrey, Konstanz, Germany) were used as reference materials for comparison. The following hypotheses were tested: (1) There is no difference in the bond strength to root dentine among experimental sealers and commercially available sealers. (2) There is no difference in the bond strength to root dentine between both experimental sealers.

\section{Material and Methods}

\section{Synthesis and Characterization of Butyl Ethylene} Glycol Disalicylate

The transesterification reaction of methyl salicylate in two different alcohols in a molar ratio of 1:3 initiated the synthesis of 1,3-butyl ethylene glycol disalicylate. Isopropoxide titanium (Sigma-Aldrich, St. Louis, Missouri, USA) was used as a catalyst. The reaction was maintained at $200{ }^{\circ} \mathrm{C}$ for about $2 \mathrm{~h}$. In order to remove the excess of methyl salicylate, the product was purified by vacuum distillation. Then, nuclear magnetic resonance spectroscopy (NMR) and Fourier transform infrared spectroscopy (FIIR) were used to characterize the butyl ethylene glycol disalicylate. The peak narrow of the hydroxyls in the spectral range from $3300 \mathrm{~cm}^{-1}$ was observed (6).

\section{Calcium Phosphate-Based Cements Formulation}

Two experimental root canal sealers (MTAe, MTAe-HA) were prepared by mixing a base paste and a catalyst paste in a ratio of 1:1 according to Vitti et al. (6). The base paste contained the synthesized component 1,3 butyl ethylene glycol disalicylate and bismuth oxide. The catalyst paste was composed of MTA, Resimpol 8, and titanium dioxide, with or without the addition of hydroxyapatite. MTA Fillapex and AH Plus were prepared following the manufacturer's instructions. The composition, manufacturers, and batch numbers of endodontic sealers are described in Table 1.

\section{Specimen Size Calculation}

Based on a previous study (12), an effect size of 0.74 was added to a power $\beta=95 \%$, and a $\alpha=5 \%$ inputs into an $\mathrm{F}$ test family for one-way analysis ( $\mathrm{G}^{*}$ power 3.1 for Macintosh). A total size of 16 slices specimens was required for this study.

\section{Tooth Selection and Preparation}

This study was approved by the Local Ethics Committee. Twenty freshly extracted human permanent maxillary central incisors with one circular canal, straight roots, and mature root apices were selected. Teeth with cracks, fractures, caries, and roots with small volume or calcifications were excluded from this study. As all materials were used in artificial canals created in root slices, the inclusion and exclusion criteria were evaluated by visual analysis during teeth selection and preparation. Specimens were cleaned by ultrasonic curettes and soaking in sodium hypochlorite solution $(\mathrm{NaOCl})$ for 10 minutes. From the cementoenamel junction, one dentine slice $(1 \pm 0.1 \mathrm{~mm}$ thick) was created using a low-speed saw with a diamond disc $(\emptyset 125 \mathrm{~mm} \times 0.35 \mathrm{~mm} \times 12.7 \mathrm{~mm}$; Buehler, Ltd. Lake Bluff, New York, USA) under continuous water irrigation. The final thickness of each slice was measured with a digital caliper with an accuracy of $0.001 \mathrm{~mm}$ (Avenger Products, North Plains, Oregon, USA). According to this procedure, twenty dentine slices were produced following this protocol (Fig. 1).

\section{Preparation of Holes to Simulate Root Canals for Push-Out Assay \\ A $0.9 \mathrm{~mm}$ spherical diamond bur (Kommet, Santo André,} São Paulo, Brazil) was used to drill four equidistant holes that simulated root canals in the coronal surface of each dentine slice. Each hole was drilled under constant water irrigation in a direction parallel to the root canal wall, maintaining a constant minimum distance of $1 \mathrm{~mm}$ between the adjacent holes, the external cementum, and the root canal lumen. These regular distances were standardized by the previous measure with periodontal probe associated with marking using a hydrographic pen. A vertical support (Dremel Workstation 220, Mount Prospect, IL, USA) ensured that drilling with diamond bur occurred perpendicularly to the axial line of coronal surface of specimens $(9,12)$. 
Subsequently, all dentine slices were immersed in a freshly prepared $2.5 \% \mathrm{NaOCl}$ for 15 min and then immersed in distilled water to remove the traces of $\mathrm{NaOCl}$ solution. The smear layer was removed using 17\% EDTA for $3 \mathrm{~min}$. The final irrigation consisted of distilled water for $1 \mathrm{~min}$, $2.5 \% \mathrm{NaOCl}$ for $1 \mathrm{~min}$, and distilled water for $1 \mathrm{~min}$.

After irrigation, the holes were dried with absorbent paper, and the slices were fixed on a glass plate. Each hole was randomly filled with one of the selected endodontic sealers: AH Plus, MTA Fillapex, MTAe, and MTAe-HA (Fig. 1). The use of a hydrographic pen for marking the holes

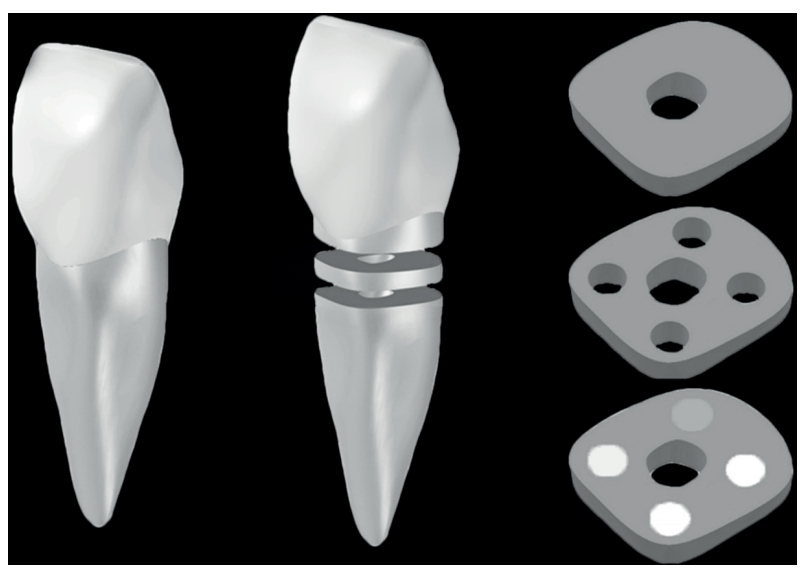

Figure 1. Selection, preparation, and filling of dentine slices. indicated the location of each sealer. The experimental root canal sealers were handled in a ratio of 1:1 (MTA:salicylate resin). Materials were gently delivered into the holes; bubble formation was avoided by manual vibration of the glass plate, in which specimens were fixed, while placing each sealer in each slice. Then, filled dentine slices were incubated in contact with gauze moistened in a phosphate-buffered saline (PBS) solution (pH 7.2) at $37{ }^{\circ} \mathrm{C}$ for 7 days. Gauze moistened with PBS solution was replaced every 2 days to replenish the buffering capacity. This experimental setup allowed the four materials to be distributed in the same dentine slice.

\section{Push-Out Assessment}

An universal testing machine (Instron, Canton, MA, USA) was used to measure the bond strengths of endodontic sealers to root dentine specimen. Loading was performed with a plunger tip of $0.7 \mathrm{~mm}$ diameter that was positioned over only one of the tested sealers for each analysis. The load was applied in a coronal-apical direction with a speed of $0.5 \mathrm{~mm} \mathrm{~min}^{-1}$, until filling-material dislocation occurred (Fig. 2). During the push-out test, a real-time software program (specific for the universal testing machine) was used to plot a load $(\mathrm{N}) \times$ displacement $(\mathrm{mm})$. The median value of push-out bond strength was calculated to obtain the MPa data according to the following formula $(9,12)$ :

Table 1. Composition, manufactures and batch numbers of root canal sealers used in this study

Materials Composition $\quad$ Manufactures and batch numbers

Dentsply, Konstanz, Germany; 1410000796 oxide, aerosol, dye, amine paste, 1-adamante amine, iron oxide, N.N'dibenzyl-5-oxanonandiamine-1,9,

TCD-diamine, calcium tungstate, silicon oil

MTA Fillapex

Salycylate resin, natural resin, diluting resin, bismuth oxide, nanoparticulated silica, MTA, pigments (MSDS data)
Base paste

Bismuth oxide (60\%), butyl ethylene glycol disalicylate $(40 \%)$

MTAe

MTAe-HA

\section{Catalyst paste MTA (60\%) \\ Pesimpol 8 (39\%)}

Titanium dioxide (1\%)

Base paste

bismuth oxide (60\%), butyl ethylene glycol disalicylate $(40 \%)$

Catalyst paste
MTA (40\%)
Resimpol $8(39 \%)$
Hydroxyapatite $(20 \%)$
Titanium dioxide $(1 \%)$

Vetec, Duque de Caxias, RJ Brazil; 010127-TB (Prepared at Federal University of Pelotas, Brazil)

Angelus, Londrina, PR, Brazil; 090605 Bandeirante Brazmo, São Paulo, SP, Brazil; 81319 Vetec, Duque de Caxias, RJ, Brazil; 06092005

Vetec, Duque de Caxias, RJ Brazil; 010127-TB (Prepared at Federal University of Pelotas, Brazil)

Angelus, Londrina, PR, Brazil; 090605 Bandeirante Brazmo, São Paulo, SP, Brazil; 81319 Sigma-Aldrich, St. Louis, MO, USA, MKBC4763V Vetec, Duque de Caxias, RJ, Brazil; 06092005 
Push-out bond strength $(\mathrm{MPa})=$ Maximum load $(\mathrm{N}) /$ Adhesion area of root canal sealers $\left(\mathrm{mm}^{2}\right)$

The adhesion area of endodontic sealers was defined by the cylinder area method, whereas $\pi=$ constant 3.14 ; $r=$ hole radius filled with root sealers $(0.45 \mathrm{~mm}) ;$ and $\mathrm{h}=$ thickness of dentine slice $(1.0 \mathrm{~mm})(9,12)$ :

Adhesion Area of Root Canal Sealers $\left(\mathrm{mm}^{2}\right)=2 \pi r \times h$

Afterwards, specimens were examined under a stereomicroscope (Optz; Opticam Microscopy Technology, Doral, Florida, USA) at 40x magnification to determine the mode of the bond failure, which was classified into three categories: (1) Adhesive failure that occurred at the material-dentine interface. (2) Cohesive failure within the filling materials. (3) Mixed failure mode.

\section{Data Presentation and Analysis}

Preliminary analysis of the raw pooled data was unable to reveal a Gaussian distribution (D'Agostino \& Person omnibus normality test); therefore, a Kruskal-Wallis test was applied to assess the effect of each endodontic sealer on the dentine bond strength. Mann-Whitney with Bonferroni

\section{Results}

All specimens had measurable push-out values and no premature failure occurred. Significant differences among medians values obtained by materials were observed $(p<0.001)$. AH Plus displayed the highest value of bond strength to root dentine $(p<0.001)$. In contrast, MTA Fillapex presented the lowest value of bond strength among all tested root canal sealers $(p<0.001)$. Experimental root canal sealers showed intermediary bond strength values with no statistical differences between them $(p>0.05)$. Figure 3 shows the variance of the bond strength data in each
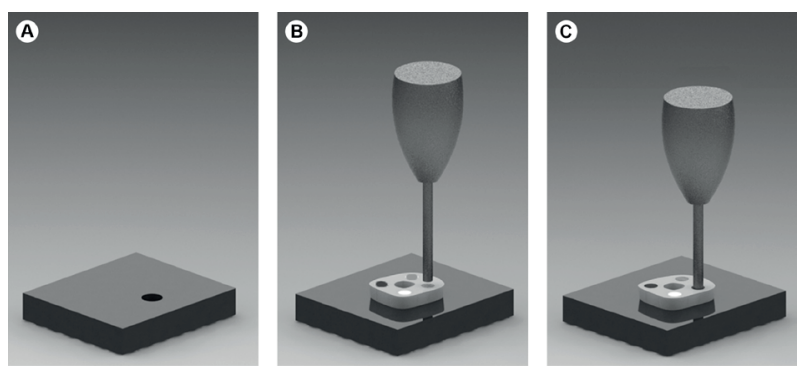

Figure 2. Push-out assessment. Device's relief for material displacement (A). Direction of the plunger tip over one root-canal sealer prior to the load application (B). Material displacement and load application in a coronal-apical direction (C). endodontic sealer.

All specimens presented the mode of the bond failure classified in cohesive failure within the filling materials.

\section{Discussion}

The present results pointed out significantly different performances among the tested materials. AH Plus, an epoxy resin sealer, produced higher bond strengths to root dentine than both experimental calcium-silicate-based sealers and MTA Fillapex. Therefore, the first hypothesis was rejected. AH Plus outperformance has been well documented in endodontic literature and is classically considered a gold standard root canal sealer $(10,13)$. Adhesion of AH Plus sealer results in great part from the formation of a covalent bond by an open epoxide ring to exposed amino groups in the collagen network (14). The strong sealing ability and mechanical interlocking of AH Plus with root dentine also results from its long setting time associated with creep capacity (15). Moreover, it could be argued that AH Plus presents a considerable cohesion between its molecules that can be translated to a great adhesion characteristic (13-15).

The two experimental sealers showed similar results; thus, we fail to reject the second null hypothesis. The similarity in the composition and properties of MTAe and MTAe-HA may explain these values. Both experimental sealers present two relevant chemical reactions: the progressive hydration of the orthosilicate ions and the reaction between MTA and butyl ethylene glycol disalicylate (6). The physical-mechanical characteristics and material set are dependent of these reactions.

Hydroxyapatite has been added in the composition of root canal sealers to improve the biological and physicochemical properties of these materials, such as the setting time and bioactivity $(2,6)$. In the present study, the addition of this component in experimental sealers did not

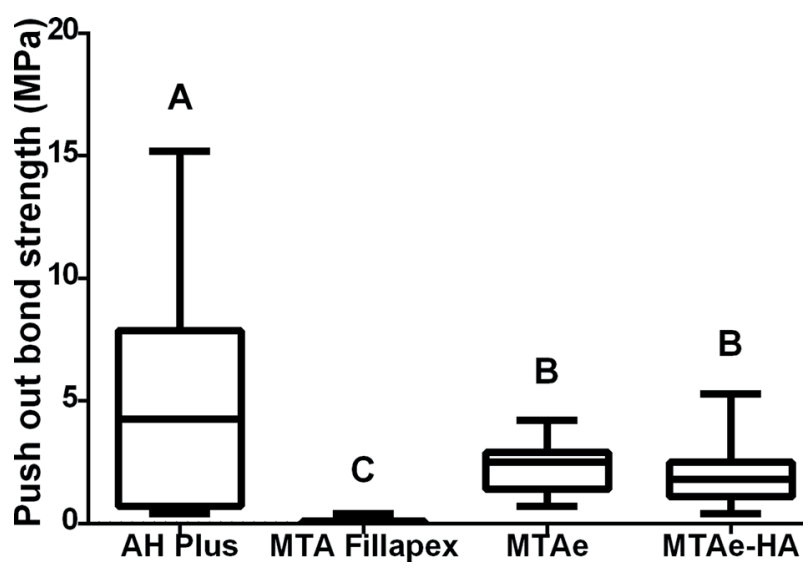

Figure 3. Box-plot with the median, the range and the minimum and maximum push-out values of the tested materials. 
influenced dentine bond strength results. The percentage of hydroxyapatite (weight 20\%) included in catalyst paste of MTAe-HA may have been insufficient to interfere on its push-out values. However, some issues regarding the addition of second sources of calcium phosphate besides MTA, such as hydroxyapatite, should be explained. When a second source of calcium phosphate is included in the composition of experimental sealers, MTA has to be removed in equal proportions. MTA and butyl ethylene glycol disalicylate-based materials need to be mixed in a ratio of 1:1 (MTA:salicylate resin) to have a complete setting reaction. As regards the variance in the material's amount in this ratio, MTA's percentage may be higher than salicylate resin's without affecting setting reaction and physical-mechanical characteristics (6). Nevertheless, if salicylate resin is added in higher proportions than MTA, the material setting reaction cannot be fully achieved. Therefore, as MTAe-HA presents a MTA:salicylate resin minimum ratio of 1:1, the addition of $20 \%$ hydroxyapatite was the maximum practicable; because the removal of MTA to increase weight of this component would lead to higher proportions of salicylate resin than MTA, and thus interfere in the material's performance.

Experimental sealers MTAe and MTAe-HA demonstrated intermediary results, presenting superior dentine bond strength outcomes when compared to a commercial MTA-based sealer, MTA Fillapex. The performance of both experimental MTA-based sealers could possibly be supported by MTA bioactivity, that is, the capacity to spontaneously produce an apatite layer when in contact with phosphatecontaining physiological fluids (16). Moreover, MTA is also known to interact with dentine to cause intratubular $\mathrm{Ca}$ and Si incorporation (17) and cause dentine remineralization (18), intrafibrilar apatite deposition (19), and the formation of tag-like structures $(10,20)$ in the presence of PBS. The ability of nucleate calcium-phosphate by calcium silicatebased materials in contact with phosphate-containing fluids is strictly correlated to the chemical composition and calcium-releasing properties (4). The nucleation of apatite at the interface produces a micromechanical bonding system to dentine that may improve the displacement resistance (21). Experimental MTA and butyl ethylene glycol disalicylate-based sealers present a higher proportion of MTA (weight 40-60\%), which may be associated with an increase in levels of biomineralization that allow for a major quantity of tag-like structures and a more-effective micromechanical bonding system when compared to MTA Fillapex. This is consistent with Vitti et al. (6) who observed that experimental sealers significantly released more calcium than MTA Fillapex.

MTA Fillapex showed the lowest value of dentine bond strength when compared to the other sealers $(p<0.05)$.
These findings are in accordance with previous reports that revealed inferior results for MTA Fillapex regarding push-out bond strength outcomes $(7,10)$. The chemical composition is one important factor that affects adhesion characteristics of an endodontic sealer. MTA Fillapex has a higher resin/ MTA proportion compared to that of experimental sealers (6). It has been observed that to MTA Fillapex complete setting reaction, a ratio of 1:1 is necessary (MTA:salicylate resin) (6). Thus, this unbalanced resin/MTA ratio may explain the lower bond strength and the properties of extended setting time and working time, excessive flow ability, and solubility as disturbance in calcium-silicate properties, which has been reported in previous studies $(5,6,22)$.

Root canal sealers containing salicylate present an initial volumetric shrinkage during setting that increases the contraction factor (23). Although manufacturers claim that MTA Fillapex presents setting expansion due to the presence of MTA, this endodontic sealer may have a higher percentage of resinous components (salicylate, diluting and natural resin) predominating over the expansion coefficient. As MTA Fillapex has an extended setting time (6), the contraction factor might increase gradually and raise the formation of gaps and channels among the sealer-dentine interface. Moreover, the excessive flow ability and solubility of MTA Fillapex may also increase dimensional changes and interfere in the sealer penetration into dentinal tubules, anatomical irregularities, or accessory canals, producing a material detachment from dentinal walls. This is consistent with previous findings that MTA Fillapex presents a considerable quantity of gaps between the sealer-dentine interface (22). In addition, this sealer has a wide range of particle sizes and an external surface with porosities (24), which represents low adhesion characteristics (1).

Push-out tests have become widely used to evaluate the quality of filling materials and to provide better understanding of the obturation process since occurrence of bond failures is an important concern in endodontic treatment $(13,14)$. Conventional push-out tests such as methodology used in De-Deus et al.(13) and Fisher et al. (14) include the chemomechanical preparation and obturation of extracted human teeth, followed by analysis in different root regions of these several specimens. This method present a major drawback of creating a reliable baseline since the variable morphology of the dentinal substrate and the intricate anatomy makes standardization challenging. In this context, the present study used a standard holes method, recently suggested by Silva et al. (9) and Scelza et al. (12), that has aspects that deserve to be addressed. To increase the internal validity of the push-out model, four artificial standard holes were created in dentine slices, providing the same dentine source to all root canal sealers. In this way, confounding factors associated with dentine 
heterogeneity - such as tooth age, mineralization, and hardness - present in different teeth and in different regions of the same root were eliminated (12). Also, a cylindrical standardized final shape with a $0.9 \mathrm{~mm}$ diameter for all holes allowed the standardization of the internal root canal anatomy among the experimental groups, which is well known as a critical confounding factor and biological bias.

Nevertheless, this study design present drawbacks, as in all in vitro methodologies, that should be indicated. The standardization of holes with a bur may dilute variables that are present in root canal anatomy in clinical situations. Additionally, to only provide a better control on the type of failure mode, the root canal space was filled only with the sealer. The advantage of this model is that the compressive load is applied on the sealer and not on the resilient material, such as gutta-percha, as the latter procedure would lead to erroneous interpretations. This also truly reflects the bond strength between the sealer and dentine $(9,12)$. However, the use of both root canal sealer and gutta-percha would present the benefit of reflecting more closely the clinical procedures in this respect.

At the present study, bond strength of root canal sealers have been evaluated in cervical third because this region presents a larger area that allowed the preparation of the four holes with $0.9 \mathrm{~mm}$ wide, respecting a constant distance of $1 \mathrm{~mm}$ between the adjacent holes, the external cementum, and the root canal lumen. The endodontic literature presents different results concerning push-out bond strength values according to root canal thirds. Studies have reported higher values of bond strengths in apical third compared to cervical third, as higher values in cervical area and similar results between root canal regions (25). In the present push-out design, dentine bond strength of sealers could not be evaluated in middle and apical regions. However, the analysis of root canal thirds was not an objective of this study.

In conclusion, experimental MTA and butyl ethylene glycol disalicylate sealers presented suitable bond strength outcomes when compared to MTA Fillapex. Therefore, the present finding adds to experimental sealers based on MTA and butyl ethylene glycol disalicylate satisfactory bond strength performance for clinical application and increases the overall knowledge about these materials that have potential to become a clinical alternative of root canal sealers.

\section{Resumo}

Esse estudo investigou a resistência de união de dois cimentos endodônticos experimentais à base de MTA e butiletilenoglicol dissalicilato: MTAe e MTAe. Os materiais de referência utilizados para comparação foram os cimentos endodônticos MTA Fillapex e AH Plus. Vinte incisivos superiores humanos foram selecionados e um slice dentinário de $1 \mathrm{~mm}$ de espessura foi obtido do terço cervical de cada raiz. Na superficie coronária de cada slice, quatro orifícios com 0,9 mm de diâmetro foram confeccionados através da dentina. Uma irrigação padronizada foi realizada e os orifícios foram preenchidos com um dos quatro cimentos endodônticos avaliados: AH Plus, MTA Fillapex, MTAe, e MTAe-HA. Os slices preenchidos foram armazenados em solução PBS $(\mathrm{pH} 7,2)$ durante 7 dias a $37^{\circ} \mathrm{C}$. 0 ensaio de push-out foi realizado por meio de um dispositivo com $0,7 \mathrm{~mm}$ de diâmetro. A carga foi aplicada com a velocidade de $0,5 \mathrm{~mm} / \mathrm{min}$ até a obtenção de deslocamento do material obturador. Os resultados foram expressos em MPa. 0 teste de Kruskal-Wallis foi aplicado para avaliar o efeito da resistência de união de cada cimento endodôntico. 0 teste de Mann-Whitney com correção de Bonferroni foi utilizado para isolamento das diferenças. 0 erro do tipo-alfa foi fixado em 0,05. Diferenças significantes entre os valores de medianas obtidos pelos materiais foram observados $(p<0,001)$. 0 AH Plus demonstrou os maiores valores de resistência de união $(p<0,001)$. Em contraste, o MTA Fillapex apresentou a menor resistência de união entre todos os cimentos testados $(p<0,001)$. Os cimentos experimentais demonstraram valores intermediários, com ausência de diferenças estatisticas entre si $(p>0,05)$. Em conclusão, os cimentos endodônticos experimentais à base de MTA e butiletilenoglicol dissalicilato apresentaram resultados adequados de resistência de união quando comparados ao MTA Fillapex.

\section{Acknowledgements}

We would like to thank the Human Teeth Biobank of the School of Dentistry of Rio de Janeiro State University (FO-UERJ) for donating the specimens used in the present study. Dr. Luciana Moura Sassone (Proc. E-26/202.839/2015) and Dr. Emmanuel João Nogueira Leal Silva (Proc. E-26/203.157/2017) are eligible with a JCNE grant from FAPERJ, Rio de Janeiro, Brazil. Dr. Emmanuel João Nogueira Leal da Silva is eligible with a CNPq grant, Brazil (304299/2017-0).

\section{References}

1. Parirokh M, Torabinejad M. Mineral trioxide aggregate: a comprehensive literature review-part I: chemical, physical, and antibacterial properties. J Endod 2010;36:16-27.

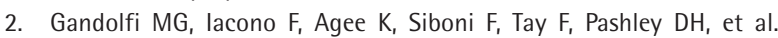
Setting time and expansion in different soaking media of experimental accelerated calcium-silicate cements and ProRoot MTA. Oral Surg Oral Med Oral Pathol Oral Radiol Endod 2009;108:e39-45.

3. Torabinejad M, Parirokh M. Mineral trioxide aggregate: a comprehensive literature review--part II: leakage and biocompatibility investigations. J Endod 2010;36:190-202.

4. Gandolfi MG, Taddei P, Modena E, Siboni F, Prati C. Biointeractivityrelated versus chemi/physisorption-related apatite precursos-forming ability of current root end filling materials. J Biomed Mater Res B Appl Biomater 2013;101:1107-1123.

5. Silva EJ, Rosa TP, Herrera DR, Jacinto RC, Gomes BP, Zaia AA. Evaluation of cytotoxicity and physicochemical properties of calcium silicatebased endodontic sealer MTA Fillapex. J Endod 2013;39:274-277.

6. Vitti RP, Prati C, Sinhoreti MA, Zanchi CH, Souza E Silva MG, Ogliari FA, et al. Chemical-physical properties of experimental root canal sealers based on butyl ethylene glycol disalicylate and MTA. Dent Mater 2013;29:1287-9124.

7. Amin SA, Seyam RS, El-Samman MA. The effect of prior calcium hydroxide intracanal placement on the bond strength of two calcium silicate-based and an epoxy resin-based endodontic sealer. J Endod 2012;38:696-969.

8. Assmann E, Böttcher DE, Hoppe CB, Grecca FS, Kopper PM. Evaluation of bone tissue response to a sealer containing mineral trioxide aggregate. J Endod 2015;41:62-66.

9. Silva EJNL, Carvalho NK, Guberman MRDCL, Prado M, Senna PM, Souza EM, et al. Push-out bond strength of fast-setting mineral trioxide aggregate and pozzolan-based cements: ENDOCEM MTA and ENDOCEM Zr. J Endod 2017;43:801-804.

10. Nagas E, Uyanik MO, Eymirli A, Cehreli ZC, Vallittu PK, Lassila LV, et al. Dentin moisture conditions affect the adhesion of root canal sealers. J 
Endod 2012;38:240-244.

11. Vane JR, Botting RM. Anti-inflammatory drugs and their mechanism of action. Inflamm Res 1998;47:S78-87.

12. Scelza MZ, da Silva D, Scelza P, de Noronha F, Barbosa IB, Souza E, et al. Influence of a new push-out test method on the bond strength of three resin-based sealers. Int Endod J 2015;48:801-806.

13. De-Deus G, Di Giorgi K, Fidel S, Fidel RA, Paciornik S. Push-out bond strength of resilon/epiphany and resilon/epiphany self-etch to root dentin. J Endod 2009;35:1048-1050.

14. Fisher MA, Berzins DW, Bahcall JK. An in vitro comparison of bond strength of various obturation materials to root canal dentin using a push-out test design. J Endod 2007;33:856-858.

15. Nunes VH, Silva RG, Alfredo E, Sousa-Neto MD, Silva-Sousa YT. Adhesion of Epiphany and AH Plus sealers to human root dentin treated with different solutions. Braz Dent J 2008;19:46-50.

16. Gandolfi MG, Taddei P, Tinti A, De Stefano Dorigo E, Rossi PL, Prati C. Kinetics of apatite formation on a calcium-silicate cement for root-end filling during ageing in physiological-like phosphate solutions. Clin Oral Investig 2010;14:659-668.

17. Han L, Okiji T. Uptake of calcium and silicon release from calcium silicate-based endodontic materials into root canal dentine. Int Endod J 2011;44:1081-1087.

18. Gandolfi MG, Taddei P, Siboni F, Modena E, De Stefano ED, Prati C. Biomimetic remineralization of human dentin using promising innovative calcium-silicate hybrid "smart" materials. Dent Mater 2011;27:1055-1069.

19. Tay FR, Pashley DH, Rueggerberg FA, Loushine RJ, Weller RN. Calcium phosphate phase transformation produced by the interaction of the
Portland cement component of white mineral trioxide aggregate with a phosphate-containing fluid. J Endod 2007;33:1347-1351.

20. Reyes-Carmona JF, Felippe MS, Felippe WT. Biomineralization ability and interaction of mineral trioxide aggregate and white Portland cement with dentine in a phosphate containing fluid. J Endod 2009;35:731-736.

21. Reyes-Carmona JF, Felippe MS, Felippe WT. The biomineralization ability of mineral trioxide aggregate and Portland cement on dentin enhances the push-out strength. J Endod 2010;36:286-291.

22. Amoroso-Silva PA, Guimarães BM, Marciano MA, Duarte MA, Cavenago $B C$, Ordinola-Zapata $R$, et al. Microscopic analysis of the quality of obturation and physical properties of MTA Fillapex. Microsc Res Tech 2014;77:1031-1036.

23. Ørstavik D, Nordahl I, Tibballs JE. Dimensional change following setting of root canal sealer materials. Dent Mater 2001;17:512-519.

24. Borges ÁH, Orçati Dorileo MC, Dalla Villa R, Borba AM, Semenoff TA, Guedes OA, et al. Physicochemical properties and surfaces morphologies evaluation of MTA FillApex and AH plus. ScientificWorldJournal $2014 ; 589732$.

25. Aksornmuang J, Foxton RM, Nakajima M, Tagami J. Microtensile bond strength of a dual-cure resin core material to glass and quartz fibre posts. J Dent 2004;32:443-450.

Received November 16, 2017 Accepted January 16, 2018 